\title{
RECUPERANDO A DIALÉTICA NO MATERIALISMO HISTÓRICO
} DE VIGOTSKI RECUPERANDO EL MATERIALISMO HISTÓRICO DIALÉCTICO EN
VIGOTSKI
RECOVERING THE DIALECTIC IN THE HISTORICAL MATERIALISM OF
VIGOTSKI

http://dx.doi.org/10.1590/1807-03102015v28n1p035

Juberto Antonio Massud de Souza

Universidade Federal de Mato Grosso do Sul, Campo Grande/MS, Brasil

\begin{abstract}
RESUMO
Desenvolvemos um estudo teórico com o objetivo central de analisar a concepção de dialética, enquanto método de análise da relação interpsíquica e intrapsíquica, no desenvolvimento da obra de Vigotski. Para isso, consideramos sua unidade como diferentes momentos de sua curta trajetória teórica. Aqui, apresentaremos os resultados, que vão de 1924 a 1927. Ao final da análise desta primeira etapa dos escritos vigotskianos, concluímos que a trajetória de apropriação do método dialético se torna completa com a crítica da crise metodológica da psicologia, fundamentando a base para a construção de uma nova psicologia.
\end{abstract}

Palavras-chave: Vigotski; dialética; psicologia soviética.

\section{RESUMEN}

Hemos desarrollado un estudio teórico con el objetivo principal de analizar la concepción de la dialéctica como método de análisis de la relación interpsíquica y intrapsíquica, en el desarrollo de la obra de Vigotski. Por lo tanto, consideramos su unidad en diferentes momentos de su corto trayectoria teórica. Aquí, presentamos los resultados, que van de 1924 a 1927. Después de la análisis de esta primera etapa de los escritos vigotskianos, llegamos a la conclusión de que el camino de apropiación del método dialéctico se completa con la crítica de la crisis metodológica en psicología, basando la base para construcción de una nueva psicología.

Palabras clave: Vigotski; dialéctica; psicología soviética.

\section{ABSTRACT}

We have developed a theoretical study with the central objective of analyzing the conception of dialectic as a method of analysis of interpsychic and intrapsychic relationship, in the development of Vigotski's writings. For this, we considered his unicity as different moments of his short theoretical path. Here, we present the results, ranging from 1924 to 1927. At the end of this first stage of analysis of the Vigotski's works, we concluded that his trajectory of appropriation of the dialectical method becomes complete with the critique of methodological crisis of psychology, stating the basis for the construction of a new psychology.

Keywords: Vigotski; dialectic; soviet psychology. 


\section{Introdução}

Este artigo tem como objetivo analisar a forma pela qual a dialética, enquanto método de entendimento da realidade interpsíquica e intrapsíquica, se manifesta no desenvolvimento da obra de Vigotski (1999a, 1999b, 2012a, 2012b, 2012c). Para isso, acatamos a divisão da sua produção em três etapas, de sua curta trajetória teórica, como proposto por Rey (2013). Aqui, apresentaremos os resultados do nosso exame da primeira parte do seu trabalho, que vai de 1924 a 1927.

Nosso esforço foi na direção de nos aprofundar em sua teoria psicológica, para entendê-la como uma unidade dialética. Ou seja, recompondo a trajetória do autor, que traçou um caminho nada linear, cheio de avanços e contradições em suas diferentes elaborações, assim como sínteses que superam as etapas anteriores. Para tanto: "defini que a obra de Vigotski teve vários momentos que exprimiram as próprias contradições de seu pensamento e do desenvolvimento acelerado de suas ideias" (Rey, 2013, p. 29).

\section{A trajetória teórica}

Por levarmos em conta que a explicação mais desenvolvida da teoria de Vigotski (2012a) se encontra na última parte de sua obra, quando demonstra maior profundidade nas explicações dos processos psíquicos, partimos, então, da retomada de seu conceito de consciência então elaborado, para compreendermos a sua trajetória teórica. Assim, pudemos recompor uma totalidade de seu pensamento psicológico, apoiados em uma análise histórica que nos mostrou o aprimoramento das principais categorias da sua obra.

Para fazer a afirmação, de 1931, de que: "La autoconciencia es la conciencia social trasladada al interior" (Vigotski, 2012c, p. 245), foi necessário ir além da psicologia tradicional, que separava as diferentes unidades funcionais da consciência para estudá-las separadamente. Considerando, então, a autoconsciência como o momento superior do processo de desenvolvimento da consciência, conseguiu entender, em 1934, a inter-relação funcional entre as diferentes unidades da consciência, chegando à conclusão de que:

El análisis atomista y funcional, que dominó la psicología científica ... dio lugar a considerar las funciones psíquicas de forma aislada y a elaborar y perfeccionar métodos de investigación psicológica aplicados al estudio de esos procesos aislados y separados entre si ... Esto implicó, naturalmente, que las conexiones interfuncionales quedaran fuera del paréntesis en calidad de constantes, sin ser tomadas en consideración en las operaciones de investigación de las diferentes funciones aisladas. (Vigotski, 2012a, p. 16)

Para chegar a essa forma de entendimento da consciência em Pensamento e Linguagem, Vigotski (2012a) teve que utilizar a dialética para a explicação da relação entre a consciência social e autoconsciência da personalidade. Isso porque sintetizou dois caminhos de estudo que, ora ganham relativa independência, ora coincidem completamente: a reflexologia mecanicista e o idealismo metafísico. Para isso, teve que considerar as discussões da consciência a partir da dialética, iniciadas na filosofia, e avançou para a psicologia, que não tinha seu equivalente. Entretanto, nesse período reduzia a materialidade aos ensinamentos da Reflexologia de Pavlov, o qual fornecia os instrumentos iniciais para lhe fundamentar, ainda que por sua origem biológica fossem mecanicistas. Por isso, vislumbra a possibilidade de superação desse limite ao reconhecer que:

En Hegel está esbozada ya la solución dialéctica de dicha cuestión. Hegel suponía que el camino certero para la solución de dicho problema no radicaba en el reconocimiento de un aspecto del interés, el subjetivo o el objetivo, sino en el reconocimiento de la unidad compleja e indivisible de ambas partes. (Vigotski, 2012c, pp. 19-20)

Assim, através da dialética tornou possível explicar o processo de desenvolvimento da consciência, tal como Hegel (2002), em sua Fenomenologia do espírito, explicava:

204 - [Das Dialetische] O dialético, como movimento negativo, tal como é, imediatamente, revela-se de início à consciência como algo a que ela está entregue, e que não é por meio da consciência mesma. Como cepticismo, ao contrário, o movimento dialético é momento da consciência-de-si - para a qual [já] não acontece, sem saber como, que desvaneça seu verdadeiro e real. Pois é essa consciência-de-si que na certeza de sua liberdade faz desvanecer até esse outro que se fazia passar por real; e não só o objetivo como tal: também sua própria relação com ele, na qual vale e é valorizada como objetiva. Assim também [faz desvanecer] seu perceber, como igualmente seu consolidar do que estava em risco de perder-se: $a$ sofistaria e seu verdadeiro determinado e fixado por sua conta.

Mediante essa negação consciente de si, garante a consciência-de-si para si mesma a certeza de sua própria liberdade: produz a experiência da liberdade, e assim a eleva à verdade. (Hegel, 2002, p. 156)

Parece-nos que acima revela sua descoberta do método para entender a unidade, mas não alcança 
o modo para demonstrar a gênese material da consciência. Assim, para Vigotski (2012c) explicar o movimento da consciência social tornando-se autoconsciencia da personalidade foi necessária a utilização da interpretação materialista da dialética de Hegel. E, para realizar a inversão materialista da dialética idealista, volta-se para o que Marx (1989) disse em $O$ Capital, que Hegel foi: "o primeiro a apresentar as suas formas gerais de movimento, de maneira ampla e consciente. É necessário pô-la de cabeça para cima, a fim de descobrir a substância racional dentro do invólucro místico" (p. 17).

O caminho para o entendimento do real, rompendo com o misticismo das explicações metafísicas, pôde ser realizado, quando reconheceu que a ideia pressupõe, necessariamente, a matéria. Sabendo disso, por que teria, então, Vigotski (2012c), um materialista, feito o caminho de volta à metafísica de Hegel?

A resposta para a pergunta coincide não apenas com a sua vida, mas com a de vários autores materialistas histórico-dialéticos. Assim, a volta de autores materialistas à obra hegeliana não se dá pelo rompimento com o materialismo; ao contrário, aparece, como dissera Vigotski (1999b), devido às exigências da dialética, ou seja: "O genial está em ver no sistema de Hegel um idealismo que pendia sobre a cabeça do materialismo. Ou seja, separar a verdade metodológica (a dialética) da falsidade real, ver que Hegel caminhava ruma à verdade mancando" (p. 267). Esta possibilidade, também, foi lembrada por Lessa (1996), quando menciona que: "Lenin, em plena I Guerra Mundial, com a enorme tarefa de reorganizar o movimento revolucionário ... e salvar os trabalhadores que se matavam nas trincheiras, tenha dedicado meses a fio a estudar... Hegel!!!” (p. 14).

Este não é um caminho novo; pois como explicou o poeta da revolução russa, Maiakóvski (2011): "Nós a dialética não aprendemos em Hegel. No fragor dos combates entrava-nos ela pelos versos" (pp. 164165). A utilização da dialética, como possibilidade de apreensão do movimento do real, foi feita a partir da apropriação materialista de Hegel, que possibilitou a Vigotski romper com o materialismo reflexológico, sem cair no idealismo metafísico. Defendemos que existe uma essencialidade na obra vigotskiana, em que ela é composta por diferentes teses e antíteses que, como polos contrários em uma unidade, afirmam ou negam posições, abrindo a possibilidade de superação. Mas apenas podemos compreendê-las na totalidade do pensamento do autor.

Com esses pressupostos definidos, para realizar a nossa análise, separamos cronologicamente os seguintes livros e textos de Vigotski do período: (a) Psicologia Pedagógica, de 1924;( b) Os Métodos de Investigação Reflexológicos e Psicológicos, 1924; (c) Psicologia Geral e Experimental, 1924; (d) Psicologia da Arte, de 1925; (e) A consciência como problema da psicologia do comportamento, de 1925; (f) Sobre o artigo K. Koffka "A Introspecção e método da psicologia"; A título de introdução, de 1926 e (g) $O$ significado histórico da crise da Psicologia: uma investigação metodológica, de 1927. O segundo e o terceiro momento, que vão, respectivamente, de 1928 a 1931 e de 1932 a 1934, serão objetos de análise em outro trabalho.

Para realizar o nosso objetivo, utilizamos a própria análise dialética como forma de tentar exaurir, ao máximo, a categoria nos textos em estudo. Buscamos ser coerentes com o método proposto por Marx, o qual é explicado por Netto (2011) quando afirma que: "conhecer teoricamente é ... saturar o objeto pensado com as suas determinações concretas" (p. 53); assim como com o que traz Vigotski (1999b), ao esclarecer que: "investigar até o fundo, esgotar uma coisa qualquer, um objeto, um fenômeno significa conhecer o mundo inteiro em todas as suas conexões"(p. 368). Sob essas orientações, a análise deve tratar o objeto em estudo a partir de suas contradições, de seu movimento real, que o explica demonstrando suas múltiplas determinações, que ora se afirmam ora se negam, formando diferentes sínteses momentâneas.

Se é verdade que a matéria precede as ideias, então, só conseguiremos compreender o caminho teórico que Vigotski (1999a, 1999b, 2012a, 2012b, 2012c) trilhou, se entendermos o processo histórico que lhe serviu de base para o avanço de suas ideias. Assim, recuperar a história significa entendê-la enquanto desenvolvimento material das formas de produção e reprodução da existência real dos homens. E reproduzir essa existência, em uma sociedade pós-revolucionária, exige superar as ideias tornadas dominantes até então. Isto está completamente de acordo com o que Marx e Engels (2013) dizem quando afirma que "conhecemos uma única ciência, a ciência da história" (p. 86). Para tanto, é necessário entender a composição não linear da história utilizando a dialética como método para a sua análise. Assim, considerar a singularidade da trajetória do próprio Vigotski significou resgatar aquilo que aconteceu no período compreendido naqueles quatro anos iniciais de sua produção teórica e, estabelecer os diferentes polos em oposição.

Ainda que saibamos que o estudo e o desenvolvimento do conceito de dialética em Vigotski tenha se iniciado antes, tomamos como marco histórico a Revolução de Outubro de 1917. Pois, como afirma 
Shuare (1990): "a psicologia soviética começa com a Revolução" (p. 24). Não porque esta seja a causa mecânica da psicologia soviética, mas tal ciência se deveu a que após a revolução, novos problemas práticos foram explicitados, e assim, apresentaram-se as necessidades de buscar soluções.

Ao elegermos o conceito de dialética para análise no corpo da obra de Vigotski, sabíamos que esta foi uma das temáticas de seus estudos. E, por esse método dialético explicou que todo conceito é um significado social e, como tal, deve ser interiorizado pelos sujeitos individualmente e, nesse processo o movimento parte da sociedade para o indivíduo, ou seja, de cima para baixo.

É assim, então, que o contextualizamos, historicamente. Um judeu, que viveu os conturbados anos da crise revolucionária no Império Russo, economicamente atrasado, onde a incapacidade do Czar lidar com as contradições internas levou a que em 1905, iniciasse um período de crise. O polo antitético ganharia força, e dentre as manifestações, vale destacar que em 1905, com o ensaio-geral da revolução, um milhão e meio de pessoas, lideradas pelo padre ortodoxo e membro da Okhrana ${ }^{1}$, Gregori Gapone, foram ao Palácio de Inverno de Nicolau II reivindicar melhores condições de vida. O Czar ordenou a morte de todos os participantes com os tiros, no episódio conhecido como o Domingo Sangrento. Rebentaram greves políticas de massas e manifestações sob a palavra de ordem: Abaixo a autocracia! O prelúdio da revolução se dava entre 1905-1907. Mas, por enquanto, nessa disputa, a tese se manteria como força principal, culminando com uma síntese parcial, que se apresentaria com a diminuição da temperatura do fervor revolucionário. Até que, com a entrada da Rússia na Primeira Guerra Mundial, em 1914, a crise, novamente, faria o motor da história entrar em ebulição, intensificando os problemas econômicos e sociais, polarizando, cada vez mais, os lados em disputa.

Explodem as manifestações contra o governo, que continuava a reprimir implacavelmente seus opositores. As Dumas Estatais ${ }^{2}$, criadas para tentar conter a crise interna do Estado russo, se mostraram inábeis na resolução dos problemas de organização política. Até que no dia 27 de fevereiro de 1917, soldados, operários e camponeses tomaram as ruas e invadiram o palácio do Czar Nicolau II. Inicia-se aí um processo revolucionário que culminaria com a Revolução de Outubro de 1917. Vigotski vivenciou todas essas transformações.

As indeléveis urgências práticas para a reconstrução da sociedade devastada pela guerra civil se tornariam exigências de trabalho para todos.
Segundo Shuare (1990), no campo da psicologia, os debates se tornaram cada vez mais polarizados entre as tendências idealistas, sintetizadas na figura de Chelpanov, e materialistas fisiológicas, na figura de Kornilov. Em 1923, é realizado o I Congresso de Psiconeurologia, o qual sob a orientação do governo soviético, que já se anunciara socialista e buscava uma nova ciência fundamentada no materialismo histórico dialético, demarca as discussões dos próximos anos. Kornilov, em oposição ao idealismo na psicologia representado por Chelpanov; e apoiado nos princípios da Reflexologia, defende a consciência como instância material, derivada do sistema nervoso central.

1924 é, politicamente, um ano cheio de crises na direção da Revolução. Lênin, o decisivo dirigente bolchevique, morre e as disputas internas no Comitê Central do PCUS pela hegemonia para uma outra política interna irão interferir diretamente nos caminhos políticos traçados para os institutos científicos nas universidades soviéticas. É um novo contexto, no qual "a depuração das universidades, a ditadura dos secretários tornaram a [revolução] sombria, enquanto a doença escavava seu sólido rosto quadrado de combatente com olhos intensos. Com a morte de Lenin, sua decisão foi tomada" (Serge, 1987, p. 224).

É, também, o momento posterior à Nova Política Econômica - NEP, que desenvolveu a economia na URSS erigindo as bases para que em poucos anos a URSS se tornasse a segunda potência mundial. Porém, em 1924 havia uma inflação que corroía o valor de todos os produtos do mercado enquanto ampliavam a fome $\mathrm{e}$ a escassez fazendo o custo de vida quase insuportável; e tornando o período de crise pós-revolucionário, mais crítico. A política de produção e distribuição de produtos tentava reorganizar as bases infraestruturais, destruídas pela crise. Essa situação crítica da revolução confirmaria as ideias de Marx e Engels (2013) quando disseram que toda revolução é: "uma revolução na qual, por um lado, sejam derrubados o poder do modo de produção e de intercâmbio anterior e o poder de estrutura social ... uma revolução na qual ... se despoje tudo o que ainda restava de sua precedente posição social" (p. 74).

Em 1924, acontece o II Congresso de Psiconeurologia. Eis, o tão comentado Congresso em que Vigotski (1999b) se destaca e, depois de sua intervenção, é convidado a compor o grupo de pesquisadores junto com Luria. Portanto, se na Rússia, a revolução havia sido feita e se a realidade concreta é sempre a base para o desenvolvimento de qualquer classe de ideias, Vigotski só poderia desenvolver uma nova teoria agora que as condições de ruptura com 
o antigo momento estavam dadas. Mas a sociedade exigia a consolidação desse processo e a educação precisava ser reestruturada.

Sabendo que as "ideias da classe dominante são, em cada época, as ideias dominantes" (Marx \& Engels, 2013, p. 47), com a chegada da Revolução, as novas teorias desenvolvidas teriam como tese a própria Revolução Russa, como forma de oposição às antigas ideias dominantes. A síntese, em Vigotski (2012b), culminaria na criação de uma nova escola de psicologia.

Mas, para chegar a esse momento de superação, precisava confrontar-se com o que tinha produzido, até então. Mas como se apropriar da dialética enquanto a ciência psicológica ainda utilizava o mecanicismo materialista? Cabia a alguém fazer isso.

Assim, iniciamos a análise do primeiro momento dos escritos de Vigotski (2003), pela publicação de seu livro Psicologia Pedagógica, concluído entre 1923 ou 1924. Esta obra visava atender a necessidade de ensinar uma visão de mundo diferente, principalmente às professoras que deveriam iniciar a educação para a construção do novo homem na sociedade pós-revolucionária. Percebe-se, nesse livro, que Vigotski reconhece a necessidade de uma psicologia original, que deveria ter dentre as suas características:

seu método dialético, que reconhece que os processos psíquicos se desenvolvem em uma vinculação indestrutível com todos os demais processos no organismo e que estão subordinados exatamente às mesmas leis de desenvolvimento que regem tudo o que existe na natureza. (Vigotski, 2003, p. 40)

Apesar de já reconhecer qual deveria ser o princípio geral explicativo das ciências, temos, um autor iniciando o seu caminho para o posterior desenvolvimento teórico que apresentaria. Mas, nesse livro, suas discussões têm um caráter bastante objetivista, que beira um simplismo, fruto da polarização entre uma psicologia de base materialista fisiológica em oposição ao idealismo metafísico. Era o resultado próprio desse momento de crise, que para levar ao desenvolvimento de uma psicologia nova, que deveria se deslocar da ideologia burguesa, é cabível que tenha se apoiado no autor russo que, em 1904, tinha ganhado o Prêmio Nobel e, assim afiançava o que dele derivava. Nessas condições, não devemos nos espantar, quando Vigotski (2003) afirma que: "a teoria dos reflexos condicionados, elaborada fundamentalmente pelo acadêmico Pavlov, elucida as leis desse mecanismo com a inegável exatidão da ciência natural experimental" (p. 53).
Isto porque, ainda, tentava conciliar, quase que de forma acrítica, esse mecanicismo objetivista com o materialismo histórico dialético. Tal como se pode confirmar quando cita diferentes obras de Marx para justificar seu posicionamento teórico-metodológico, como, por exemplo, as Teses sobre Feuerbach, Contribuição crítica à economia política e $O$ capital, assim como Do socialismo utópico ao socialismo cientifico, de Engels.

Importante notar que uma das citações de Marx é feita para fundamentar uma categoria dialética histórica que se tornaria central em diversos de seus textos: a crise. Diz, assim: "Marx destacou que o mecanismo econômico, com a ajuda das crises e das consequentes reduções e ampliações da produção, tornam necessária a existência de um exército de reserva de proletários" (Vigotski, 2003, p. 184). Se é a própria crise que explicita os pólos contraditórios no desenvolvimento econômico, seria ela, também, que mostraria, na psicologia, os diferentes movimentos opostos do desenvolvimento do indivíduo. Assim, a crise é utilizada desde para explicar a situação caótica da psicologia, até para explicar as crises durante o processo de desenvolvimento da criança. Parece ter sido essa a categoria que lhe demonstrou a necessidade de se apropriar da dialética.

Utiliza-se, assim, da dialética de Marx, para explicar as leis do desenvolvimento da sociedade, e da reflexologia de Pavlov, para explicar as leis de desenvolvimento do indivíduo. Isso se explica por Pavlov, por mais reflexológico e mecanicista que fosse, tinha sua base em um materialismo fisiológico, ainda que essas diferentes visões da materialidade ainda não lhe permitissem explicar a unicidade dos aspectos constituintes dos homens.

Como podemos perceber, Psicologia Pedagógica é o livro inicial, de um autor que está aprofundando seus estudos em psicologia, que conhecia como suporte para os processos criativos artísticos, ao mesmo tempo em que tenta dominar a dialética como método de análise aplicado à realidade concreta e, portanto, incluindo o aspecto material. Mas logo as contradições entre o materialismo mecanicista e o materialismo histórico-dialético tornar-se-iam evidentes demais para serem deixadas em segundo plano. A árdua tarefa de reestruturar as bases teórico-metodológicas da psicologia, aqui, ainda tem um caráter germinal.

Em 1924, escreve o texto Os métodos de investigação reflexológicos e psicológicos, que mantém, ainda, uma análise pavloviana bastante forte. Nesse curto escrito, apresentado no II Congresso de Psiconeurologia de Leningrado, já reconhece limites no autor em que se apoiava: "Pavlov assinala as vantagens 
da escolha precisamente do reflexo de secreção da saliva nos cachorros ... Isso era extraordinariamente importante ... Mas as novas tarefas exigem também novos meios, os avanços obrigam a mudar de rota" (Vigotski, 1999b, p. 7).

Aqui, lança a ideia de uma crise metodológica na psicologia e os objetivos de reestruturar os métodos dessa ciência, problematizando os becos sem saída da reflexologia. Começa, cada vez mais, a opor diferentes elementos das diversas teorias científicas em litígio, tentando entender o caráter de totalidade das ciências, deixando de considerá-las de forma fragmentada e atomística. Assim, destaca as contradições entre os diferentes pólos dentro da unidade de análise que era a psicologia, e com isso: "Tudo desmoronou, tal é o resultado da crise e não apenas na Rússia. Mas também a reflexologia foi parar num beco sem saída, depois de ter erguido os alicerces" (Vigotski, 1999b, p. 26).

Assim, seria necessário problematizar a crise da ciência psicológica. Vigotski (1999b) firma sua posição materialista para, depois, fundamentar a dialética, enquanto método, em uma ciência não dialética. Diz: "Ser materialista em fisiologia não é difícil, mas provem como sê-lo em psicologia e, se não o conseguirem, continuem a ser idealistas" (p. 27).

Ainda em 1924, escreve um Prólogo à $3^{\mathrm{a}}$ edição do livro de A. F. Lazurski, um tradicional psicólogo e psiquiatra russo, que redige um manual de educação utilizado para o ensino superior. Se o eclético Lazurski explicava os processos de sentimentos religiosos em um capítulo de sensações básicas, a partir da psicologia experimental, Vigotski (1999b) disse "as disciplinas psicológicas nas escolas superiores atravessam um período de crise aguda" (p. 33); e delimita alguns objetivos da nova psicologia, quando diz que é necessário: "revisar os fundamentos e princípios da psicologia à luz do materialismo dialético e ligar a elaboração da investigação científica e teórica, assim como o ensino dessa ciência, a premissas de caráter filosófico mais gerais e fundamentais" (pp. 33-34). A crise era tão evidente que uma referência para o ensino superior confundia processos básicos com processos superiores.

Nessa citação, deixa claro que existia um direcionamento teórico-metodológico pelo qual se guiaria. Tinha-se uma teoria geral para as ciências, e cabia confrontá-la com o que da antiga psicologia deveria servir de base para a nova. Reconhece que: "Ainda não se criou um novo sistema de psicologia científica que, sem se apoiar em absoluto nos anteriores, seja capaz de organizar seu próprio curso" (Vigotski, 1999b, p. 39). As críticas à reflexologia de Pavlov continuariam:
É necessário assinalar ... que a reflexologia representa outro ponto de vista, tão inaceitável quanto o da psicologia empírica ... Esse materialismo fisiológico unilateral está tão distante do materialismo dialético quanto o está o idealismo da psicologia empírica. (Vigotsky, 1999b, p. 51)

Mas, como uma psicologia dialética ainda não existia, seria, então, necessário se apoiar nos fundamentos básicos do que, até então, havia sido produzido naquela determinada ciência. Sobre o porquê de usar, então, os elementos do sistema psicológico anterior, afirma:

Não há dúvida de que muito do que ali ocupa o primeiro lugar ocupará aqui o último. Mas, enquanto não tiver sido criado o novo sistema, não temos outro remédio senão aceitar temporariamente, ainda que de forma crítica, na ciência e no ensino, o antigo aparato da ciência. (Vigotski, 1999b, p. 53)

Eis um Vigotski (1999b) inquieto, incomodado com a situação na qual a psicologia se encontrava; chegando ao ponto de, em um prólogo de livro, tomar tempo para falar da necessidade de construir uma nova psicologia. O problema, para ele, estava claro. O princípio que deveria construir a nova psicologia, também estava diante de seus olhos. Faltava, então, um trabalho de análise exaustivo, que procurasse exaurir, ao máximo o que a própria psicologia tinha dado conta de fazer.

Se o alicerce em que uma estrutura é erigida mantém-se sobre bases instáveis, é questão de tempo para que uma tempestade ponha abaixo tudo aquilo que, de forma tacanha, havia sido construído. É assim que funcionam, também, as ciências humanas: se, por sobre um princípio frágil se constroem teorias inteiras, o trabalho de derrubada de toda a estrutura é, praticamente, inevitável. Eis a teoria da crise, do materialismo histórico-dialético, encontrando um exemplo vivo na crise das ciências humanas do inicio do século XX. Eis a apropriação da dialética, não como mera palavra utilizada em um trabalho, mas como uma relação específica a ser demonstrada a partir da análise concreta. Mas, antes de Vigotski (1999b) destruir os alicerces da velha psicologia, e o reconstruir com as novas pedras, mais resistentes, rejeitadas anteriormente, nosso autor tinha que defender sua tese de doutorado. Eis a bonança antes da inevitável tempestade.

Em 1925, defende sua tese de doutorado, que culminaria com o escrito Psicologia da Arte. Logo em seu capítulo inicial, abre o livro com uma discussão sobre a teoria marxista da arte e a psicologia:

Aqui tivemos como fio condutor a famosa tese do marxismo segundo a qual o enfoque sociológico da 
arte não anula o estético, mas, ao contrário, escancara diante dele as portas e o pressupõe como, segundo Pliekhánov, seu complemento. (Vigotski, 1999a, p. 2)

Partindo de uma assertiva de Plekhánov ${ }^{3}$, autor que, ainda no antigo Império Russo, desenvolveu as primeiras análises marxistas da realidade russa, e que foi responsável pela primeira tradução do Manifesto do Partido Comunista de Marx e Engels para o russo; Vigotski (1999a) defende a tese de que "a arte é o social em nós" (p. 315).

Plekhánov, além de fazer parte do grupo Emancipação do Trabalho, que estabeleceu uma série de correspondências entre militantes russos e Karl Marx, culminando em uma discussão, no prefácio de $O$ Capital, a respeito da propriedade comunal da Rússia czarista, e seu papel em um momento de crise do capitalismo; fez, também, análises sobre arte. Não por acaso, Vigotski (1999a), afirma que "ninguém, como Pliekhánov, explicou com tanta clareza a necessidade teórica e metodológica do estudo da psicologia para uma teoria marxista da arte" (p. 10). Ainda na sua tese, para a análise de poemas de Alexander Blok e Ivan Bunin, Vigotski (1999a) utiliza a contradição dialética, para afirmar que:

durante séculos os especialistas em estética vêm afirmando a harmonia da forma e do conteúdo, dizendo que a forma ilustra, completa, acompanha o conteúdo, e de repente descobrimos que isto é o maior dos equívocos, que a forma combate o conteúdo, luta com ele, supera-o, e que nessa contradição dialética entre conteúdo e forma parece resumir-se o verdadeiro sentido psicológico da nossa reação estética. (p. 199)

Vigotski (1999a) já tinha dominado o entendimento que para se realizar uma análise dialética, era necessário contrapor polos aparentemente irreconciliáveis a todo momento. Também sabia que não se poderia harmonizar elementos contraditórios. Mas como sair do polo negativo da crítica para avançar, em direção à superação? Antes do salto qualitativo é necessário saber a direção para onde se deve pular, caso contrário, o salto de qualidade pode se transformar em um salto mortal. Mas, enquanto isso, Vigotski (1999a), ainda, se posicionava no pólo da crítica:

Nós realmente começamos a entender por que os
extremistas de esquerda na nossa arte lançam a
fórmula: a arte como método de construção de vida
... lançam a ideia do sentir dialeticamente o mundo
através da matéria, coincidem integralmente com
aquelas leis da arte reveladas pela psicologia. (p. 328)

Em Psicologia da Arte, percebemos que Vigotski (1999a) amplia suas leituras de Marx e Engels, e continua a usar citações destes para subsidiar e justificar o embasamento teórico para o seu trabalho. Assim, utiliza-se de diversos excertos de A Ideologia Alemã, Crítica à Economia Política, e da carta que Engels enviou a Mehring. Com esse arsenal teórico, analisa grandes autores clássicos e contemporâneos da literatura e da poesia russa, como Gógol, Tolstoi, Puchin, Tchekov e Maiakóvski.

Ainda em 1925, escreve A consciência como problema da psicologia do comportamento. Nele demonstra que continua se esforçando para romper com a reflexologia de Pavlov, e aprofundar as explicações dos processos psíquicos a partir de uma perspectiva dialética, tal como podemos perceber quando afirma que existe um: "caráter catastrófico da luta do processo dinâmico e dialético entre o mundo e o homem e no interior deste, que se denomina de comportamento" (Vigotski, 1999b, pp. 68-69).

Em 1926, escreve "A introspecção e o método da psicologia": A título de introdução, sobre o artigo de Koffka. Aqui, Vigotski (1999b) já aponta o que considerava ser uma qualidade geral que deveria guiar o desenvolvimento de uma nova psicologia. Afirma, então, o monismo como, necessariamente, norteador das explicações integrais da teoria e se apoia nas leis fundamentais da dialética de Hegel, escritas em sua Lógica e retomadas por Engels (2000), na Dialética da Natureza $a^{4}$. Assim:

A nova teoria parte da identidade fundamental das leis que constroem os "conjuntos" ... na física, na fisiologia, na psique. A nova teoria admite o princípio dialético da transição da quantidade em qualidade, quando o utiliza para explicar a diversidade qualitativa das vivências. (p. 90)

Entramos, finalmente, no ano de 1927, que, em nossa análise, é o período final da primeira etapa da trajetória de Vigotski (1999b). Ela fecha esse período com o texto: O significado histórico da crise da Psicologia: uma investigação metodológica. Aqui se dá o primeiro grande salto qualitativo em sua obra, ou momento em que a quantidade de materiais escritos nos anos anteriores, se transforma em qualidade, na teoria de Vigotski (1999a). Se, anteriormente, se localizava ao lado da crítica negativa, seria então, a hora de superar este pólo para, enfim, dar o salto rumo à superação metodológica. Que lhe dá o caminho para solucionar, ainda, que parcialmente, um grande número de problemas que vinham sendo anunciados no decorrer de sua obra.

Consegue se apropriar do que de melhor, em termos de princípios metodológicos, o materialismo histórico-dialético criou. Como diz Vigotski (1999b) na epígrafe do texto, se "a pedra que rejeitaram os 
construtores, essa veio a ser a pedra angular" (p. 203), a solução apresentada, só poderia ser uma reconstrução da ciência psicológica, com novos princípios gerais. $\mathrm{O}$ objetivo dele era claro, a criação de uma ciência geral, que possibilitasse explicar os aspectos fragmentados de seu desenvolvimento, pois: "na futura sociedade, a psicologia será, na verdade, a ciência do homem novo. Sem ela, a perspectiva do marxismo e da história da ciência seria incompleta" (p. 417). Mas antes do novo, é necessário analisar do ponto mais desenvolvido do pólo negativo da crítica, afinal:

Dessa crise metodológica, da evidente necessidade de direção que mostram uma série de disciplinas particulares - num determinado nível de conhecimentos - de coordenar criticamente dados heterogêneos, de sistematizar leis esparsas, interpretar e comprovar os resultados, de depurar métodos e conceitos, de estabelecer princípios fundamentais, em síntese, de dar coerência ao conhecimento, é de tudo isto que surge a ciência geral. (Vigotski, 1999b, pp. 203-204)

O problema da psicologia não estava no acúmulo de dados empíricos, isso ela já tinha feito em grande escala, mas na ausência do meio com o qual se deveria interpretar os dados da realidade. Essa incapacidade metodológica levou a psicologia a se cindir em torno de dois polos distintos: a ideologia e a ciência. Sobre as quais nos diz que:

no campo da ideologia rege a lei, descoberta por Engels, da concentração de ideias em torno de dois pólos - o idealismo e o materialismo ... A natureza social das idéias manifesta-se com muito mais facilidade em um fato filosófico do que como fato científico: termina o seu papel de agente ideológico oculto disfarçado de fato científico e fica desmascarada, começando então a participar como um elemento a mais na luta dos tipos de idéias. (Vigotski, 1999b, p. 222)

Ou seja, retoma, mais uma vez, a ideia de polarização desenvolvida na obra Dialética da Natureza, de Engels (2000). Essa polarização: "colocou na ordem do dia a divisão das duas psicologias através da metodologia" e, dando sequência, "mas o indubitável é que a psicologia não avançara até que se crie essa metodologia e que este será o primeiro passo adiante" (Vigotski, 1999b, p. 397).

Para a solução dos problemas que impediam a construção dos princípios de uma psicologia geral, Vigotski (1999b) aponta uma citação de Engels (2000), que direciona o entendimento da dialética, que: "se concebe como a ciência das leis mais gerais de todo devir. Isso significa que as suas leis devem reger tanto o devir da natureza e a história humana quanto o que se dá no campo do pensamento" (p. 247). Havia encontrado o método adequado para o entendimento dos princípios gerais que regem o processo de constituição dos fenômenos da realidade, deixando claro que, na psicologia:

Essas palavras encerram a chave da psicologia geral como parte da dialética: essa correspondência entre pensamento e realidade que se dá na ciência constitui ao mesmo tempo objeto e o critério fundamental e inclusive o método da psicologia geral, isto é, seu princípio geral. (Vigostski, 1999b, pp. 247-248)

A dialética materialista é, finalmente, aplicada em uma análise exaustiva por Vigotski (1999b), como método para a superação do entendimento das relações entre as diversas escolas psicológicas. Faz, assim, a análise crítica e exaustiva da própria psicologia, pois somente a dialética, com as leis que a regem, é capaz de explicar a relação entre indivíduo e natureza, assim como o próprio desenvolvimento do psiquismo do indivíduo.

Qual era seu objetivo? Exaurir os problemas das teorias psicológicas em conflito, para entendê-las em sua totalidade; considerando, sempre, a unidade que existe dentro da diversidade nada coerente da realidade. É isso que ele chama de uma investigação metodológica verdadeira, ou seja, buscar a "análise dos processos em sua essência”.' (Vigostski, 1999b, p. 372). Eis a saída da crise ${ }^{5}$ : construir uma psicologia geral, cujos novos princípios teórico-metodológicos, fossem capazes de unificar, levando-se em consideração todas as contradições existentes, na produção que já havia sido feita. Era um problema de método, eis, então sua solução.

Interessante observar que neste texto, pela primeira vez, ele utiliza de citações de Lenin, e o faz, na discussão entre premissas materialistas, que admitem "um determinado pressuposto: concretamente da premissa da realidade, de que esta existe objetiva e regularmente fora de nós e é cognoscível. Isto é, como afirmou várias vezes V. I. Lenin, a própria essência do materialismo" (Vigostski, 1999b, p. 371). Ainda sobre a necessidade de se partir da matéria, afirma: "Lenin escrevia aos construtores de Deus que os diferenciava pouco dos que buscavam: em geral, o que importa é aceitar ou rejeitar o diabólico, porque entre aceitar um diabo azul ou amarelo, há pouca diferença" (Vigostski, 1999b, p. 379).

A característica que explicita, fundamentalmente, esse fim do primeiro período é seu rompimento parcial com a reflexologia e o aprofundamento dos princípios dialéticos, saindo, cada vez mais, de seu entendimento superficial. Consegue se apropriar tão bem da dialética que termina esse momento com uma complexa análise 
da psicologia. Havia, enfim, dominado-a na prática. Sinaliza, também, a utilização de escritos de Lenin, que seriam utilizados, como teses de trabalho, em ocasiões vindouras.

\section{Conclusão}

Terminada a discussão e a análise, podemos apontar algumas características bem fortes na trajetória de Vigotski (1999a, 1999b). Principalmente em seus textos iniciais, até em 1926, ainda não havia conseguido se livrar, por completo, da herança da reflexologia russa de Pavlov e, portanto, carrega-a, inclusive quando trata da dialética. Mas, gradativamente, começa a apontar as próprias limitações metodológicas desse materialismo fisiológico, e pôde, então, apreender a crise da psicologia. O caminho que trilha é do polo negativo da crítica à superação desse momento.

O primeiro salto qualitativo vigotskiano se deu em um texto que traz a necessidade de utilizar novos princípios gerais para o desenvolvimento da psicologia, ainda em formação. Se o desmoronamento foi inevitável, era hora, então, de reconstruir, por sobre bases sólidas, tudo aquilo que se contrapunha a nova psicologia.

O estrago da tempestade estava concluído. Foi hora de fazer o balanço do que restou, e de fundamentar a base para a próxima construção: "a crise é destruidora, mas benéfica: nela se oculta $o$ auge da ciência, seu enriquecimento, sua força, e não a impotência e a falência" (Vigotski, 1999b, 324).

Por entre as trincheiras da luta ideológica, travadas por sobre as ruínas do antigo regime, foi forjado o entendimento do novo homem na psicologia. O homem não cindido, inquebrantável, compreendido em sua unidade integral e temperado no árduo trabalho de reconstrução de uma sociedade devastada. A antiga atomística divisão entre os diferentes elementos que interiorizam, no homem, a concretude das relações sociais estava enterrada por de baixo do tapete da história. A tarefa do primeiro momento de Vigotski (1999a, 1999b) estava cumprida.

Mas como a realidade objetiva determina, necessariamente, o desenvolvimento das ciências humanas, o que acontecia na URSS, iria, também, afetar a próxima fase da teoria de Vigotski (2012a, $2012 b, 2012 c)$. Do ponto de vista político, 1927, dez anos após a Revolução, é o ano em que se entra no mais terrível e dramático momento da história revolucionária do século $\mathrm{XX}$ : a contra revolução se fortaleceria, ganhando força. Isso repercutiria em todos os âmbitos da vida soviética, inclusive na produção da obra de Vigotski (2012a, 2012b, 2012c).
Se for verdade o que disse o Mefistófeles, de Goethe (1984), em que "tudo vai perecer" (p. 188), seria então o processo de decadência da revolução?

Serge (1987) nos disse: "o Termidor soviético se realizou em novembro de 1927, nos dias de aniversário da tomada do poder. Em dez anos, a revolução esgotada se voltara contra si mesma" (p. 257). Os problemas da realidade objetiva continuavam a eclodir. As disputas internas do Comitê Central se tornavam, cada vez mais, implacáveis. Os campos de trabalhos forçados estavam lotados de dissidentes. A Tcheka ${ }^{6}$ liquidava os adversários sem deixar vestígios. Os revolucionários da geração de 1917 se suicidavam em grande quantidade. O que guardaria o momento seguinte, então, para Vigotski? Eis que responderemos no segundo artigo, que dará continuidade a nossa investigação da trajetória dialética de Vigotski.

\section{Notas}

Okhrana foi a polícia secreta no regime do czar Alexandre III da Rússia.

2 Duma Estatal do Império Russo foi uma assembléia legislativa criada ao final do Império Russo. Deveu-se à pressão da Revolução Russa de 1905 e sua função era a de um orgão consultivo.

Plekhánov morreria em 1918, um ano após a Revolução Russa, e seria, ainda, renegado por uma parte dos bolcheviques por ter ficado ao lado dos mencheviques.

4 “ As leis da dialética são, por conseguinte, extraídas da história da Natureza, assim como da história da sociedade humana. Não são elas outras senão as leis mais gerais de ambas essas fases do desenvolvimento histórico, bem como do pensamento humano. Reduzem-se elas, principalmente, a três: (a) A lei da transformação da quantidade em qualidade e vice-versa; (b) A lei da interpenetração dos contrários; (c) A lei da negação da negação. Essas leis foram estabelecidas por Hegel, de acordo com sua concepção idealista, como simples leis do pensamento" (Engels, 2000, p. 34).

5 Para Shuare (1990): “Corresponde a L. S. Vigotski él mérito invalorable de ser el primero en aplicar el materialismo dialéctico e histórico a la ciencia psicológica y de haberla colocado, con ello, "sobre seus pies", provocando una verdadera revolución copernicana en la psicologia (Shuare, 1990, p. 57).

6 Polícia política criada na União Soviética, em 1917. Foi a continuadora do deplorável trabalho da Okrana.

\section{Referências}

Engels, F. (2000). Dialética da natureza (6 $6^{\mathrm{a}}$ ed.). São Paulo: Paz e Terra. (Original publicado em 1833)

Goethe, J. W. (1984). Fausto. São Paulo: Ediouro.

Hegel, G. W. F. (2002). Fenomenologia do espirito ( $6^{\mathrm{a}}$ ed.). Petrópolis, RJ: Vozes.

Lessa, S. (1995). Crítica ao praticismo revolucionário. Acesso em 10 de janeiro, 2014, em http://www.sergiolessa.com/ artigos 92 96/praticismo 1995.pdf 
Maiakóvski, V. (2011). Vida e poesia (2ª ed.). São Paulo: Martin Claret.

Marx, K. (1989). O capital. São Paulo: Civilização Brasileira.

Marx, K. \& Engels, F. (2013). A ideologia alemã. São Paulo: Boitempo. (Original publicado em 1846)

Netto, J. P. (2011). Introdução ao estudo do método de Marx. São Paulo: Expressão Popular.

Rey, F. L. G. (2013). O pensamento de Vigotsky: contradições, desdobramentos e desenvolvimento. São Paulo: Hucitec.

Serge, V. (1987). Memórias de um revolucionário. São Paulo: Companhia das Letras.

Shuare, M. (1990). La psicología soviética tal como la veo. Moscou: Progreso.

Vigostski, L. S. (1999a). Psicologia da arte. São Paulo: Martins Fontes.

Vigostski, L. S. (1999b). Teoria e método em psicologia. São Paulo: Martins Fontes.

Vigostski, L. S. (2003). Psicologia Pedagógica. São Paulo: Artmed.

Vigostski, L. S. (2012a). Obras Escogidas - II. Madrid: Machado Libros.

Vigostski, L. S. (2012b). Obras Escogidas - III. Madrid: Machado Libros.

Vigostski, L. S. (2012c). Obras Escogidas - IV. Madrid: Machado Libros.

\section{Agradecimento}

À agência de fomento, CAPES - Bolsa Demanda Social.

Submissão em: 14/09/2014

Revisão em: 10/05/2015

Aceite em: 24/06/2015

Juberto Antonio Massud de Souza é mestre em Psicologia pela Universidade Federal de Mato Grosso do Sul - UFMS. Endereço: UFMS - Centro de Ciências Humanas e Sociais. Cidade Universitária s/n - Caixa Postal 549. Campo Grande/MS, Brasil. E-mail: xjubertox@hotmail.com 